\title{
Weight and Body Image Attitudes: Correlation and Gender Differences among A Sample of University Students in Alexandria.
}

\author{
${ }^{1}$ Amany A Salama, ${ }^{1,2}$ Doaa Genena \\ ${ }^{1}$ Faculty of Allied Medical Sciences, Pharos University, Alexandria, Egypt \\ ${ }^{2}$ Medical Research Institute, University of Alexandria, Egypt
}

\begin{abstract}
Background: Body image does not merely reflect the heavenly grant of the individual or the observational remarks of other important people. The perceived constituent of body image refers mostly to body size assessment. Alteration of body size that goes in the direction of overestimation was usually seen as a predictor for the development of eating disorders. Objective: The purpose of the study is to investigate weight and body image attitudes and perceptions, and the presence of risky weight control practices among a sample of Pharos university students. Method: A 398 university students (males and females) aged 18-26 years, who were chosen randomly from Pharos University campus during the spring semester 2016-2017, were asked to fill out a self-reported weight and body image inventory, adapted from The University of Florida Counseling Services, that included their weight, and height. Results: Mean BMI was $24.84 \pm 4.35$ and a prevalence of overweight and obesity of $41 \%$ was found among students, $55.5 \%$ were of normal weight (50\% of males compared to $60 \%$ of females), and $3.5 \%$ were underweight. Relations between sex and body image attitude: a total of 33.9\% for both sexes were at risk; (More than 5 false answers) was (19.9\%) among male students and $(41.6 \%)$ among female students. Female participants revealed a significant correlation between their self-reported current weight and dissatisfaction about their body image in relation to males $(\mathrm{p}=0.005)$. Conclusion: The results of this study indicate that both genders are subject to some degree of risky behaviors as they reported a higher degree of negative responses in relation to weight and body image. By investigating weight and body image related attitudes; researchers can better determine where their weight management and eating disorder prevention programming efforts can best be targeted.
\end{abstract}

Keywords: Body image Disordered eating Obesity in Egypt

Corresponding author: Amany A Salama Email: amanysalama@ hotmail.com

\section{Introduction}

Body image is a multifaceted, subjective and vibrant concept that encircles a person's perceptions, beliefs, and feelings about the body. ${ }^{1}$ Body image is not limited to the visual characteristics of the person, but is further concerned with health, skills, and sexuality. ${ }^{2}$

Even though it is nearly constant over time, body image actually changes in certain contexts (specific age susceptibility and fluctuation after media exposure or health status modifications). Body image does not merely reflect the heavenly grant of the individual or the observational remarks of other important people. While these factors certainly influence body satisfaction, what is critical is the way our bodies are self-experienced and evaluated. 
The final result depends on personal factors (personality, self-esteem), interpersonal factors (family, peers and media messages), biological factors (genetic traits, increased BMI, a series of pathologies), and cultural factors (social values and norms). ${ }^{3}$

Each aspect of body image (perceptual, attitudinal and behavioral) can now be assessed by an array of dedicated instruments. The perceived constituent of body image refers mostly to body size assessment. Alteration of body size that goes in the direction of overestimation was usually seen as a predictor for the development of eating disorders. Yet, when researchers separated the sensory components of self-perception (meaning the visual system responses) and the nonsensory components (meaning those cognitive and affective elements that interpret the visual input), they concluded that among anorexic patients, alteration in body size was not due to the differences in sensory sensitivity, but to the disturbances in weight and body image attitudes. ${ }^{4}$

Body dissatisfaction, or a negative evaluation of the size, shape, or appearance of one's body, has been linked to plentiful awkward behaviors, including binge eating, self-induced purging or laxative misuse. $^{5}$

Data on body image self-perception are scarce especially in the Eastern Mediterranean Region EMR; these data are needed in order to design interventions to introduce or improve an effective nutrition and weight counseling among adolescents. Recent EMR studies revealed increasingly westernized views of the ideal body image where thin body image is now considered a beautiful feature of females. ${ }^{6}$

According to the World Health Organization, eating disorders are mental disorders involving physiological and psychological effects associated with a preoccupation with food and body image.
Eating disorders ED are not 'diets gone wrong', but are serious and potentially life threatening mental illnesses, young people experience eating disorders at higher rates than others in the general population, with as many as $15 \%$ of adolescent females and $3 \%$ of males experiencing an eating disorder. $^{7}$

Research in the field of eating disorders is limited in the Middle East. In a Lebanese study clinicians across Lebanon filled individual questionnaires about their 2013 ED outpatients $(n=104)$ and participated in focus groups. Results showed that bulimia nervosa was the most prevalent ED $(46.1 \%)$ followed by anorexia nervosa (39.4\%) and binge eating (14.4\%) and there was a general delay in seeking help which made patient recovery more difficult. Studies emphasize the critical need for a public health approach to ED awareness that could help in developing preventive and remedial educational programs targeting youth in the Middle East. $^{8-11}$

This research reviewed the results of student's attitudes toward their weight and body image and categorized students as being either normal or at-risk based on their responses aiming to investigate weight and body image attitudes and perception, and the presence of risky weight control practices among a sample of Pharos university students.

\section{Method}

The data for this study were derived from a convenient sample of 398 students (141 males and 257 females). The sample was randomly collected from Pharos university students; $36.7 \%$ of students were at allied medical science, $11.8 \%$ at dentistry, 10.6 $\%$ at mass communication, $10.3 \%$ at engineering, 9.8 at pharmacy and drug manufacturing, $6 \%$ at physical therapy, $5.3 \%$ at arts and design, $4.3 \%$ at languages 
\& translation, $2.5 \%$ at tourism and hotel management, $1 \%$ at financial and administrative sciences and $0.8 \%$ at legal studies and international relations.

\section{Data Collection Tool:}

A weight and body image inventory, adapted from The University of Florida Counseling Services, and tested by a recent study $^{12}$ was administered to students during the spring semester 2016-2017. This inventory was comprised of 10 true/false statements addressing attitudes related to weight and body image. The responses were analyzed, with five or more negative responses representing a higher degree of risk, to determine the degree of weight and body image dissatisfaction in relationship to self-reported current and goal weights among college aged students. Institutional review board approval was received, and informed consent was obtained from all participants.
The original questionnaire was in English, and it was translated into Arabic using two independent forward translations by the researchers (Genena D and Salama AA). An expert committee (Three members of staff from PUA) also reviewed the translated questionnaire to ensure face validity; i.e. the degree to which a procedure, especially a psychological test or assessment, appears effective in terms of its stated aims. In addition, the data collecting team's native Arabic speakers examined the translated version, reviewed any instances of misunderstandings and decisions were made accordingly. The translation focused on and ensured the equivalence of meaning, and the assessment of the same attributes, i.e., cross-cultural and cross-language equivalence. The final translated Arabic questionnaire was piloted among a sample of Allied Medical Sciences Faculty students, with no comments returned that needed amending. ${ }^{13-14}$

\section{Data Analysis}

Data from weight history forms, weight and body image attitudes inventories, was retrieved and entered an excel spreadsheet. The statistical analysis via SPSS (Statistical Package for the Social Sciences) version 20 program was utilized for this study. Qualitative data were described using number and percent and was compared using Chi square test. Statistically significant at $\mathrm{p} \leq 0.05$. A Pearson Correlation was done for correlations. Normally quantitative data was expressed in mean $\pm \mathrm{SD}$ and was compared using student t-test.

\section{Results}

Students with a mean age of $20.6 \pm 1.59$ years participated in this study. The average weight and height were $70.46 \pm$ $16.15 \mathrm{~kg}$ and $167.9 \pm 10.41 \mathrm{~cm}$, respectively. Mean BMI was $24.84 \pm 4.35$. 
A prevalence of overweight and obesity of $41 \%$ was found among students, $55.5 \%$ were of normal weight $(50 \%$ of males compared to $60 \%$ of females), and $3.5 \%$ were underweight.

The weight and body image attitudes inventory consisted of statements about the level of comfort participants feel surrounding their weight. This inventory also had statements related to how they feel regarding their body shape and size. Females demonstrated more at-risk attitudes (41.6\%), a higher degree in negative responses, while males were 80.1 $\%$ at normal attitude.

Table 1- shows that, in the total sample, one third (33.9\%) were having negative

Table (1): Relations between sex and body image attitude

\begin{tabular}{|c|c|c|c|c|c|}
\hline \multirow[b]{2}{*}{$\begin{array}{l}\text { Body image } \\
\text { attitude }\end{array}$} & \multicolumn{2}{|c|}{ Sex } & \multirow[b]{2}{*}{$\begin{array}{c}\text { Total } \\
(\mathbf{n}=398) \\
\mathbf{N}(\%)\end{array}$} & \multirow[b]{2}{*}{$\chi^{2}$} & \multirow[b]{2}{*}{$\mathbf{p}$} \\
\hline & $\begin{array}{c}\text { Male } \\
(\mathrm{n}=141) \\
\mathrm{N}(\%)\end{array}$ & $\begin{array}{c}\text { Female } \\
(\mathrm{n}=\mathbf{2 5 7}) \\
\mathrm{N}(\%)\end{array}$ & & & \\
\hline $\begin{array}{l}\text { Normal (less than } 5 \\
\text { false answer) }\end{array}$ & $113(80.1)$ & $150(58.4)$ & $263(66.1)$ & \multirow{2}{*}{$19.26^{*}$} & \multirow{2}{*}{$<0.001^{*}$} \\
\hline $\begin{array}{l}\text { At risk (More than } 5 \\
\text { false answer) }\end{array}$ & 28 (19.9) & 107 (41.6) & 135 (33.9) & & \\
\hline
\end{tabular}

Table (2): Correlation between self-reported current weight and weight and body image attitudes

\begin{tabular}{lcccccc}
\hline & \multicolumn{4}{c}{ Body image attitude } & \multicolumn{2}{c}{ Total } \\
\cline { 2 - 8 } & \multicolumn{2}{c}{$\begin{array}{c}\text { Male } \\
(\mathbf{n}=\mathbf{1 4 1})\end{array}$} & \multicolumn{2}{c}{$\begin{array}{c}\text { Female } \\
(\mathbf{n}=\mathbf{2 5 7})\end{array}$} & \multicolumn{2}{c}{$\begin{array}{c}\text { Total } \\
(\mathbf{n}=\mathbf{3 9 8})\end{array}$} \\
\hline $\begin{array}{l}\text { Weight } \\
(\mathbf{k g})\end{array}$ & $\mathbf{r}$ & $\mathbf{p}$ & $\mathbf{r}$ & $\mathbf{p}$ & $\mathbf{r}$ & $\mathbf{p}$ \\
\hline
\end{tabular}

$\mathrm{r}_{\mathrm{s}}$ : Spearman coefficient

$*$ : Statistically significant at $\mathrm{p} \leq 0.05$

between the participant's self-reported current weight and their attitudes about weight and body image. Results showed a small but statistically significant positive correlation present among females, $\mathrm{r}=$ $0.133, \mathrm{n}=257, \mathrm{p}=0.033$.

Regarding body image attitude and BMI; $(66.1 \%)$ of students had normal attitude, $(3.4 \%)$ of them were under weight, $57.4 \%$ were normal weight, $27.4 \%$ were overweight, and $11.8 \%$ were obese), while attitude; of them $20.7 \%$ were males compared to $79.3 \%$ females. While two thirds of the students $(66.1 \%)$ were normal (43\% of the male students compared to $57 \%$ of the female students).

At risk students (More than 5 false answers) forms $19.9 \%$ of male students, $41.6 \%$ of female students, with a total of $33.9 \%$ for both sexes $(\mathrm{p}<0.001)$. In Table 2; a Pearson Correlation was completed looking at the correlation 
female participants (Table 5), then the overweight and obese categories; even though these findings were not statistically significant.

Correlations between self-reported weight and dissatisfaction about body image and personal feelings - of happiness or sadness - in males and females are shown in (Tables 6 and 7); female participants revealed a significant correlation between their self-reported current weight and dissatisfaction about their body image in relation to males, compared using student t-test $(\mathrm{p}=0.005)$.

\section{Discussion}

Weight-loss behaviors are highly prevalent among adolescents, and body weight perception motivates weight control

Table (3): Relations between BMI and body image attitude

\begin{tabular}{|c|c|c|c|c|c|c|c|}
\hline \multirow[b]{2}{*}{$\begin{array}{c}\text { Body } \\
\text { image } \\
\text { attitude }\end{array}$} & \multicolumn{4}{|c|}{ BMI } & \multirow[b]{2}{*}{$\begin{array}{c}\begin{array}{c}\text { Total } \\
(n=398)\end{array} \\
\text { N }(\%)\end{array}$} & \multirow[b]{2}{*}{$\chi^{2}$} & \multirow[b]{2}{*}{$\mathbf{p}$} \\
\hline & 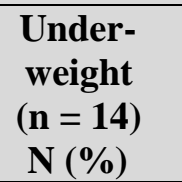 & $\begin{array}{c}\text { Normal } \\
\text { weight } \\
(\mathbf{n}=222) \\
\mathbf{N}(\%)\end{array}$ & $\begin{array}{c}\text { Over - } \\
\text { weight } \\
(\mathbf{n}=115) \\
\mathbf{N}(\%)\end{array}$ & $\begin{array}{c}\text { Obese } \\
(\mathrm{n}=47) \\
\mathrm{N}(\%)\end{array}$ & & & \\
\hline $\begin{array}{l}\text { Normal } \\
(\text { false <5) }\end{array}$ & $9(64.3)$ & $151(68.0)$ & $72(62.6)$ & $31(66.0)$ & $263(66.1)$ & \multirow{2}{*}{1.011} & \multirow{2}{*}{0.799} \\
\hline $\begin{array}{l}\text { At risk } \\
(\text { false } \geq 5 \text { ) }\end{array}$ & $5(35.7)$ & $71(32.0)$ & $43(37.4)$ & $16(34.0)$ & 135 (33.9) & & \\
\hline
\end{tabular}

Qualitative data were described using number and percent and was compared using Chi square test

Table (4): Relations between BMI and body image attitude in male group

\begin{tabular}{|c|c|c|c|c|c|c|c|}
\hline \multirow[b]{2}{*}{$\begin{array}{l}\text { Body image } \\
\text { attitude }\end{array}$} & \multicolumn{4}{|c|}{ BMI } & \multirow[b]{2}{*}{$\begin{array}{c}\begin{array}{c}\text { Total } \\
(n=141)\end{array} \\
\text { N }(\%)\end{array}$} & \multirow[b]{2}{*}{$\chi^{2}$} & \multirow[b]{2}{*}{${ }^{{ }^{M C}} \mathbf{p}$} \\
\hline & $\begin{array}{l}\text { Underweight } \\
\qquad \begin{array}{c}(\mathbf{n}=\mathbf{8}) \\
\mathbf{N}(\%)\end{array}\end{array}$ & $\begin{array}{c}\text { Normal } \\
\text { weight } \\
(\mathbf{n}=76) \\
\mathbf{N}(\%)\end{array}$ & $\begin{array}{c}\begin{array}{c}\text { Over } \\
\text { weight } \\
(\mathrm{n}=42) \\
\mathrm{N}(\%)\end{array} \\
\end{array}$ & $\begin{array}{c}\text { Obese } \\
(\mathbf{n}=15) \\
\mathbf{N}(\%)\end{array}$ & & & \\
\hline $\begin{array}{l}\text { Normal } \\
(\text { false }<5)\end{array}$ & $8(100)$ & $59(77.6)$ & $32(76.2)$ & $14(93.3)$ & $113(80.1)$ & \multirow{2}{*}{3.69} & \multirow{2}{*}{0.287} \\
\hline $\begin{array}{l}\text { At risk } \\
(\text { false } \geq 5 \text { ) }\end{array}$ & $0(0)$ & $17(22.4)$ & $10(23.8)$ & $1(6.7)$ & 28 (19.9) & & \\
\hline
\end{tabular}

Qualitative data were described using number and percent and was compared using Chi square test, Monte Carlo test

In the current study; there was a prevalence of overweight and obesity of $41 \%$ among students, more than half of the students were of normal weight, females demonstrated more at-risk attitudes (41.6 practices. However, little is known about the association of weight and body image attitudes, and risky weight control practices among adolescents in Egypt. The aim of this study is to investigate the relationships between body weights, and body image attitudes, gender differences and behaviors putting this age group at risk of developing disordered eating. The weight and body image attitudes inventory is comprised of 10 true/false statements addressing attitudes related to weight status and body image. Participants were categorized as either presenting normal or at-risk attitudes based on their negative responses to these statements. (Appendix1) 
is significantly higher among females. This was stated by a recent study at Assiut University in Egypt; the variables associated with BIC did not differ substantially between male and female students. BMI, depressive symptoms, body image perception as being too fat, and selfrated health were associated with BIC for both genders. Males' BIC still requires more attention, and also necessitates the development/refinement of methods to specifically assess male BIC. ${ }^{15}$

In 1986, Nasser $\mathrm{M}^{16}$ compared two samples of Arab female students attending London and Cairo Universities; he found that $12 \%$ of Cairo group had eating disorders compared to $22 \%$ of London group. Concern with body weight existed in a society presumed to have different values. Western cultural norms related to body image were thought to be partly responsible for causing high prevalence of eating disorder in London group. Al-Isa ${ }^{17}$ reported that there may be a greater social pressure in Europe to be thin, perhaps, than in the Arab Gulf countries; as he found that in Kuwait there were a trend to tolerate fatness, and there were no social condemnation or disapproval against adiposity.

As regards to gender, the study findings confirmed the expected link between gender and body image attitude, males tended to have a more 'positive' body image attitude compared to females. Of the 141 male participants in the current study; significantly fewer males $(20 \%)$ responded with at-risk attitudes (a higher degree of negative response) in regards to weight and body image compared to the female participants $(42 \%)$ out of 257 . ( $\left.p<0.001^{*}\right)$. This is supported by other studies showing

Table (5): Relations between BMI and body image attitude in female group

\begin{tabular}{|c|c|c|c|c|c|c|c|}
\hline \multirow[b]{2}{*}{$\begin{array}{c}\text { Body } \\
\text { image } \\
\text { attitude }\end{array}$} & \multicolumn{4}{|c|}{ BMI } & \multirow{2}{*}{$\begin{array}{c}\text { Total } \\
(n=257)\end{array}$} & \multirow[b]{2}{*}{$\chi^{2}$} & \multirow[b]{2}{*}{${ }^{\mathrm{MC}} \mathbf{p}$} \\
\hline & $\begin{array}{l}\text { Underweight } \\
\qquad \begin{array}{c}(\mathbf{n}=6) \\
\mathbf{N}(\%)\end{array}\end{array}$ & $\begin{array}{c}\begin{array}{c}\text { Normal } \\
\text { weight }\end{array} \\
(\mathrm{n}=146) \\
\mathbf{N}(\%)\end{array}$ & $\begin{array}{c}\begin{array}{c}\text { Over } \\
\text { weight } \\
(\mathbf{n}=73) \\
N(\%)\end{array} \\
N(\%)\end{array}$ & $\begin{array}{c}\begin{array}{c}\text { Obese } \\
(n=32)\end{array} \\
N(\%)\end{array}$ & & & \\
\hline $\begin{array}{l}\text { Normal } \\
(\text { false }<5)\end{array}$ & $1(16.7)$ & $92(63.0)$ & $40(54.8)$ & $17(53.1)$ & $150(58.4)$ & & \\
\hline $\begin{array}{l}\text { At risk } \\
(\text { false } \geq 5)\end{array}$ & $5(83.3)$ & $54(37.0)$ & 33 (45.2) & 15 (46.9) & 107 (41.6) & 0.12 & 0.096 \\
\hline
\end{tabular}

Qualitative data were described using number and percent and was compared using Chi square test, Monte Carlo test

that women were more likely to perceive themselves as being overweight than men. $(18,19)$ Yet still about $20 \%$ of males were atrisk; i.e. not only females are at risk for eating disorder and disordered eating, males can be at risk as well. Adolescent males failing to achieve the muscular body idol by their faulty eating habits and entering the overweight zone become dissatisfied with their weight and body image.

An inadequacy in eating disorder research is the minor amount of information relating to the male population.
Historically, male presentations of eating disorders have been perceived as rare and atypical - a perception that has resulted in the systematic underrepresentation of males in ED research. Further, the marginalization of males from ED research has hindered the assessment and clinical management of these presentations. Yet an emerging body of evidence relating to muscularity-oriented eating is created in relation to the existing classification framework of eating disorders. ${ }^{20}$

A study in KSA found that none of the obese male students reported being 
dissatisfied about their body shape compared to obese females. Almost similar percentage of male and female students on overweight category reported dissatisfied concerning their body shape. Significant difference was observed among male and female students about their body shape satisfaction. Results indicated that body shape dissatisfaction and inactive lifestyle were prevalent among females than males and age, weight, BMI and marital status were predictors of body shape dissatisfaction. $^{21}$

Table (6): Correlations between weight and satisfaction in Male \& Female

\begin{tabular}{lcc}
\hline \multirow{2}{*}{ Satisfaction } & \multicolumn{2}{c}{ Weight $(\mathbf{k g})$} \\
\cline { 2 - 3 } & $(\mathbf{n}=\mathbf{1 4 1})$ & $\begin{array}{c}\text { Female } \\
(\mathbf{n}=\mathbf{2 5 7})\end{array}$ \\
\hline Satisfied & $75.70 \pm 17.34$ & $65.58 \pm 12.18$ \\
\hline Unsatisfied & $74.90 \pm 16.47$ & $72.22 \pm 18.90$ \\
\hline $\mathbf{t}(\mathbf{p})$ & $0.228(0.820)$ & $2.896^{*}\left(0.005^{*}\right)$ \\
\hline Normally quantitative data was & expressed in mean \\
\pm SD and was compared using & student t-test. *: \\
Statistically significant at $p \leq 0.05$
\end{tabular}

Table (7): Correlations between weight and feeling happy in Male \& Female

\begin{tabular}{lcc}
\hline \multirow{2}{*}{$\begin{array}{c}\text { Feeling } \\
\text { happy }\end{array}$} & \multicolumn{2}{c}{ Weight $(\mathbf{k g})$} \\
\cline { 2 - 3 }$(\mathbf{n = 1 4 1})$ & $\begin{array}{c}\text { Female } \\
(\mathbf{n}=\mathbf{2 5 7})\end{array}$ \\
\hline Yes & $74.25 \pm 18.41$ & $66.46 \pm 14.25$ \\
\hline No & $78.47 \pm 13.40$ & $68.88 \pm 15.52$ \\
\hline T (p) & $1.353(0.178)$ & $1.301(0.194)$ \\
\hline
\end{tabular}

Normally quantitative data was expressed in mean $\pm S D$ and was compared using student $t$-test

One past research study found that $20 \%$ of young college men displayed eating attitudes and behaviors characteristic of eating disorders and disordered eating. ${ }^{22}$ As well, a cross-sectional study, utilizing the Eating Attitudes Test-40, found the prevalence of eating disorders among a group of female college students to be an alarming $13.8 \% .^{23}$ Over the past 10 years, research had paid more attention to body image in boys and men. ${ }^{24} \mathrm{~A}$ substantial amount of empirical evidence exists indicating that males experience dissatisfaction with aspects of their appearance and weight, albeit to a lesser extent than females. It has been acknowledged that the nature of male body dissatisfaction is perhaps more complex than female body dissatisfaction. While females strive for thinner bodies, males consistently report wanting to be more muscular. $^{25}$

Women tend to have a more 'negative' attitude towards their bodies, and the desire to be thin is a critical factor in women's outlook toward their bodies and body image perception. Looking at the correlation between the participant's selfreported current weight and their attitudes about weight and body image; results showed a statistically significant positive correlation present among females, $\mathrm{n}=257$, $\mathrm{r}=0.133, \mathrm{p}=0.033$. Hence, dissatisfaction with one's weight and attempting to achieve one's ideal body shape are seen as risk factors of eating disorders and healthendangering behaviors.

Another study found that even though it was mostly women who tended to perceive themselves as "too fat", more than one third of men reported feeling "too fat". This suggested that men too are prone to the perceived 'problems' of body dissatisfaction, and hence, as women, might comprise a potential risk-group for the development of eating disorders. ${ }^{26}$

A study at the University of NebraskaLincoln stated that; as the self-reported current weight of participants increased, the risk (a higher degree of negative response) in their attitudes about weight and body image was higher. Females demonstrated more at-risk attitudes (37.4 $\%$ ), a higher degree in negative responses, while males were $72.3 \%$ at normal attitude. $^{12}$

In 2013 a study documented that, among weight-losing teens, $88.5 \%$ of students perceived themselves as overweight even though only $19.2 \%$ were overweight. Reducing fat intake, exercising and increasing intake of fruits and vegetables 
and decreasing intake of sugar were the most commonly reported methods to lose weight. $^{27}$ A cross-sectional survey from seven universities in the UK stated that; more females $(35 \%)$ than males $(8 \%)$ reported being moderately or markedly concerned with their body image. For both genders, BIC was associated with a higher level of depressive symptoms and to variable extents, with nutrition and year at university. ${ }^{28}$

Identification and early intervention are a critical part of the mental health promotion spectrum. Individuals who are showing warning signs are at much higher risk of developing an eating disorder. Further, research shows significantly improved outcomes for individuals who are identified and treated early in the course of illness. $^{29,30}$

Media promotion of the ideal body as slimness for women and muscularity for men, has led to increasing numbers of both genders reporting dissatisfaction with their bodies and trying to change using weight control products. ${ }^{31}$

Cultural influences were found to be important, with body size underestimations occurring in cultures where a larger body is found to be desirable. Researchers found that overweight and obese men underestimate their weight status, and that men are less accurate in their categorizations than women. ${ }^{32}$ Contrary to what we reported; in adult Saharawi refugees, participants had a higher desire to gain weight in comparison to the desire to lose weight, which could indicate how satisfied they are with their perceived body size. $^{33}$

In consistency with our study results; many overweight boys in the Balearic Islands, Spain were satisfied with their body image while practically all overweight girls reported wishing a thinner body. Meal patterns and food consumption were associated with body dissatisfaction and overweight status among adolescents. $^{34}$

Compared to the aforementioned studies $^{12,28}$, the current study showed a higher prevalence of at risk behaviors of $42 \%$ among females. For adolescent girls and women, the gap between the average and the ideal has expanded; models used to weigh about $8 \%$ less than the average woman, they now weigh $23 \%$ less. $^{35}$ Adolescent boys face a similar dilemma; as the ideal body image for men has become increasingly muscular. ${ }^{36}$ Therefore, female and male adolescents face huge challenges as they create their body image while map reading cultural images that are often beyond their reach.

A recent study on similar population reported a high percentage of faculties' students consider themselves as overweight or obese, despite nearly half of them had normal BMI. More than one third of them were practicing weight reducing measures (44.8\% Female, $41.2 \%$ Male). Weight loss behaviors were more prevalent among females, young students, living in urban areas and students affiliated to faculty of education. ${ }^{37}$

Changes in cultural norms over time as a result of media exposure, globalization and urbanization may lead to changes in body image perceptions; this is best demonstrated by the fact that after almost three decade from Nasser $M,{ }^{16}$ research; Kabir et al, in $2013^{38}$ reported that body image perceptions and a desire to be thinner were strongly related to body image dissatisfaction and that thinness is becoming more desired in Kuwaiti society than the plump body image of the past. While Shaban et al, in $2016^{39}$ reported that females in the obese category were the most dissatisfied with their body image, followed by those in the overweight category.

The utilized inventory had statements related to how participants feel in regards 
their body shape and size. The results of the female participants revealed $a$ significant correlation between their selfreported current weight and dissatisfaction about their body image $(\mathrm{p}=0.005)$. Female students in our sample were unsatisfied with body weights greater than $\pm 72 \mathrm{~kg}$, while those with body weights around $65 \mathrm{~kg}$ were satisfied.

A prior research on female university students has concluded that only $15.8 \%$ of the students were satisfied with their weight and more than half had tried to lose weight during the two years preceding the study; showing that the higher the mean BMI the less satisfied the students were with their weight, these were similar to our findings except in that the weight rather than the BMI that counted in the current study. ${ }^{40}$

In Brazil; to explore the relationship between body image dissatisfaction and eating patterns in adolescents, results indicated that body image dissatisfaction was identified in $19.5 \%$ of the adolescents. $^{41}$ In Zarqa-Jordan, Zawawi, compared between participants by age, education, marital and work status show that younger, married, not working overweight and obese women are more prone to score higher on negative perceptions and dissatisfaction with body shape scales. $^{42}$

Failure to recognize weight correctly may bring about a false sense of security around health and contribute to persistence of unhealthy lifestyles. Consequently, discrepancies between true weight and weight perception can have serious implications and can be associated with eating disorder tendencies. ${ }^{43,44}$

Students perceiving themselves as overweight engaged in unsupervised exercise activities and reduced food intake with lack of proper knowledge of dietary guidelines or appropriate weight loss goals. In line for the high prevalence of body weight misperception existing among adolescents; promotion of healthy body image perception and healthy eating practices is pivotal. It is sensible to implement health promotion programs to raise awareness regarding concepts of healthy body image in relation to medical definitions of overweight to improve precision of weight perceptions, promote healthy realistic body weight and lead to healthier eating and promote physical activity. Health promoting strategies and activities should address the standard body weight SBW according to frame size ${ }^{45}$ as it is more realistic than ideal body weight.

\section{Conclusions}

The results of this study indicate that both genders are subject to some degree of risky behaviors as they reported a higher degree of negative responses in relation to weight and body image. There is scarcity of data on the association between body selfperception, body image attitudes and weight loss patterns in Egypt; further studies are needed to explore this enigma. By investigating weight and body image related attitudes; researchers can better determine where their weight management and eating disorder prevention programming efforts can best be targeted.

\section{Recommendations}

Implementation of a health promotion program to raise awareness regarding concepts of a healthy body image; improve precision of weight perception, promoting healthy realistic weight loss goals and healthier eating and physical activity practices. The use of SBW charts estimated with linear regression formulas; which take into consideration, age, sex, height and frame size, with 10-pound increments in each frame size; small, medium, and large. That is a 30-pound swing for any given height. Since media 
holds an important place in influencing body image perception, media can be used by health care providers to transport healthful messages.

\section{Limitations}

The results of the research are limited by the use of a convenience sample of students from just one university which may not be a representative of all university students in Egypt. Furthermore, Pharos university students are usually of high socio-economic standard; therefore, samples from different universities may provide a more inclusive picture of university students taking into consideration socio-economic status.

Although researchers have validated the accuracy of self-reported height and weight data, women may underestimate weight by $2.1 \mathrm{~kg}$. Thus, the weight and BMI changes calculated in these studies may be underestimates. Heavier people may underestimate their weight, and height tends to be over reported. ${ }^{(46)}$

However, baseline information about weight status and body image attitudes among a sample of university students was certainly obtained from the present study.

\section{References:}

1. Millstein RA, Carlson SA, Fulton JE, Galuska DA, Zhang J, Blanck HM, et al: Relationships between body size satisfaction and weight control practices among US adults. Medscape J Med 2008, 10:119.

2. Luskin Biordi D.; Mccann Galon P., "Body Image", in "Chronic Illness: Impact and Intervention" (Eighth edition), ed. I.M. Lubkin and P.D. Larsen , Jones \& Bartlett Learning, Burlington, 2011, pp. 133-150.

3. Naigaga et al. Body size perceptions and preferences favor overweight in adult Saharawi refugees. Nutrition Journal. 2018; 17: $1-8$.
4. Neagu A. Body image: A theoretical framework. Proc. Rom. Acad. 2015; 17(1): 29-38.

5. Roosen K.M., Mills J.S. Body Image, Overview. (2014) In: Teo T. (eds) Encyclopedia of Critical Psychology. Springer, New York, NY.

6. Yahia, N, El-Ghazale, H, Achkar, A, Rizk, S. Dieting practices and body image perception among Lebanese university students. Asia Pac J Clin Nutr. 2011; 20(1): 21-28.

7. National Eating Disorders Collaboration. Eating Disorders in Australia 2016. Available from: http://www.nedc.com.au/eatingdisorders-in-australia.

8. Zeeni N, Safieddine H. Doumi R. Eating Disorders in Lebanon: Directions for Public Health Action. Community Ment Health J. 2015; 53: 4-11.

9. Nobakht M, Dezhkam M. An epidemiological study of eating disorders in Iran. Int J Eat Disord. 2000; 28(3):265-71.

10.Al-Adawi S, Dorvlo AS, Burke DT, Moosa S, Al-Bahlani S. A survey of anorexia nervosa using the Arabic version of the EAT-26 and "gold standard" interviews among Omani adolescents. Eat Weight Disord. 2002; 7(4):304-11.

11.Garcia-Burgos D, Maglieri S, Vögele C, Munsch S. How Does Food Taste in Anorexia and Bulimia Nervosa? A Protocol for a QuasiExperimental, Cross-Sectional Design to Investigate Taste Aversion or Increased Hedonic Valence of Food in Eating Disorders. Front Psychol. 2018; 9: 264.

12.Estes EN, Kohnke C . Attitudes of College Students in Relationship to Weight and Physical Activity. Nutrition \& Health Sciences Dissertations \& Theses. University of Nebraska-Lincoln. 2012.

13.WHO - Process of translation and adaptation of instruments. Available from: http://www.who.int/substance_abuse/research_ tools/translation/en/

14.Maneesriwongul W1, Dixon JK. Instrument translation process: a methods review. J Adv Nurs. 2004; 48(2): 175-86.

15.El Ansari W, Dibba E, Labeeb S, Stock C. Body image concern and its correlates among male and female undergraduate students at 
Assuit University in Egypt. Global Journal of Health Science. 2014; 6: 105-17.

16.Nasser M, "Comparative study of the prevalence of abnormal eating attitudes among Arab female students of both London and Cairo Universities," Psychological Medicine, vol. 16, no. 3, pp. 621-625, 1986.

17.Al-Isa AN, "Dietary and socio-economic factors associated with obesity among Kuwaiti college men," British Journal of Nutrition, vol. 82, no. 5, pp. 369-374, 1999.

18.Unterhalter G, Farrell S, Mohr C. Selective memory bias for words reflecting sex-specific body image concerns. Eat. Behav. 2007, 8, 382-389.

19.Tiggemann M. The impact of adolescent girls" life concerns and leisure activities on body dissatisfaction, disordered eating, and self-esteem. J. Genet. Psychol. 2001; 162: 133142.

20.Murraya SB, Nagata JM, et al. The enigma of male eating disorders: A critical review and synthesis. Clinical Psychology Review. 2017; 57: 1-11.

21.AL-Otaibi HH, Nassef SL, Raouf TA. Body shape dissatisfaction, weight status and physical activity among a sample of university students in Saudi Arabia. Food and Nutrition Sciences. 2013; 4: 616-25.

22.O'Dea J, Abraham S. Eating and Exercise Disorders in Young College Men. Journal of American College Health. 2002; 50(6):273-8.

23.Tozun M, Unsal A, Avranci U, Arslan G, Arslantas D, Koc F. Prevalence of eating disorders and risk profile in a group of female college students. Internet Journal of Epidemiology. 2009; 7(1).

24.Cafri, G., Yamamiya, Y., Brannick, M., \& Thompson, J. K. The influence of sociocultural factors on body image: A meta analysis. Clinical Psychology: Science and Practice. 2005; 12(4): 421-33.

25.Cafri, G., Thompson, J. K., Ricciardelli, L. A., McCabe, M. P., Smolak, L., \& Yesalis, C. Pursuit of the muscular ideal: Physical and psychological consequences and putative risk factors. Clinical Psychology Review. 2005; 25: 215-39.

26.El Ansari W, Clausen SV, Mabhala A, Stock C. How Do I Look? Body Image Perceptions among University Students from
England and Denmark. Int. J. Environ. Res. Public Health 2010, 7, 583-595.

27.Bhurtun DD, Jeewon R. Body Weight Perception and Weight Control Practices among Teenagers. ISRN Nutrition Volume 2013, Article ID 395125, 6 pages

28.El Ansari W, Dibba E, Stock C. Body image concerns: levels, correlates and gender differences among students in the United Kingdom. Cent Eur J Public Health. 2014; 22 (2): 106-117

29.Eating disorders prevention, treatment \& management: An Evidence Review. The National Eating Disorders Collaboration. 2010. Available from: http://www.nedc.com.au/files/pdfs/NEDC_Evi dence\%20Review_Final.pdf

30.Paxton, S. J., Neumark-Sztainer, D., Hannan, P. J., \& Eisenberg, M. E. Body dissatisfaction prospectively predicts depressive mood and low self-esteem in adolescent girls and boys. Journal of Clinical Child and Adolescent Psychology. (2006); 35: 539-549.

31.Luevorasirikul K, Gray NJ, Anderson CW. An interview study of influence of the media on body image in university students. International Journal of Pharmacy Practice 2006:14: 042; A33.

32.Gardner RM. Weight status and the perception of body image in men. Psychology Research and Behavior Management. 2014:7 175-184.

33. Naigaga et al. Body size perceptions and preferences favor overweight in adult Saharawi refugees. Nutrition Journal. 2018; 17: 1-8.

34.Bibiloni1 MM, Pich J, Pons A, Tur JA. Body image and eating patterns among adolescents. BMC Public Health 2013, 13:1104

35.Borzekowski DLG, Bayer AM. Body Image and Media Use Among Adolescents Adolescents' construction of body image. Adolesc Med.(2005); 16: 289 - 313.

36.Leit RA, Pope HG, Gray JJ. Cultural expectations of muscularity in men: the evolution of Playgirl centerfolds. Int $\mathrm{J}$ Eat Disord 2001;29:90 - 3 .

37.Amin DA, Anas El Wogoud H. Body Weight Perception and Dietary Control 
Methods among Egyptian University Students. Journal of American Science. 2016; 12(3): $105-15$.

38.Kabir Y, Zafar TA, Waslien C. Relationship between perceived body image and recorded body mass index among Kuwaiti female university students. Journal Women \& Health. 2013; 53: 693-705.

39. Shaban LH, Vaccaro JA, Sukhram SD, Huffman FG. Perceived Body Image, Eating Behavior, and Sedentary Activities and Body Mass Index Categories in Kuwaiti Female Adolescents. International Journal of Pediatrics. 2016; 2016: 1- 7.

40.Cilliers J, Senekal M, Ernesta K. The association between the body mass index of first-year female university students and their weight-related perceptions and practices, psychological health, physical activity and other physical health indicators. Public Health Nutrition. 2005;9(2):234-243.

41.Ribeiro-Silva RC, Fiaccone RL, ConceiçãoMachado MEPD, Ruiz AS, Barreto ML, Santana MLP. Body image dissatisfaction and dietary patterns according to nutritional status in adolescents. J Pediatr (Rio J). 2018; 94(2): 155-61.
42.Zawawi JA. Relationships between Body Mass Index, Body Image Dissatisfaction and Psychological Distress among Fitness Center Female Users in Zarqa-Jordan. International Journal of Humanities and Social Science. 2014; 4: 109-30.

43.Sirang Z, Bashir $\mathrm{H}$, Jalil B et al. Weight patterns and perceptions among female university students of Karachi: a cross sectional study. BMC Public Health 2013; 13:230.

44.Epuru S, Eideh A, Shamsuddeen S, et al. Self-reported weight patterns and perceptions among female students of Saudi Arabia: A cross sectional survey. International Journal of Nutrition and Food Sciences 2013; 2(6): 3605.

45. Frisancho AR. New standards of weight and body composition by frame size and height for assessment of nutritional status of adults and the elderly. Am J Clin Nutr. 1984; 40(4):808-19.

46.Bowring AL, Peeters A, Freak-Poli R, Lim MSC, Gouillou M, Hellard M. Measuring the accuracy of self-reported height and weight in a community-based sample of young people. BMC Medical Research Methodology 2012, 12:175.

Appendix-1: Weight and Body Image Attitudes Inventory

\begin{tabular}{|c|c|}
\hline Question & "Weight and Body Image Attitudes Inventory \\
\hline 1. & I rarely talk negatively about my body. \\
\hline 2. & I do not weigh myself more than once a week. \\
\hline 3. & $\begin{array}{l}\text { If appearance didn't matter in our society, I would still } \\
\text { exercise the same amount that I do now. }\end{array}$ \\
\hline 4. & I rarely compare my looks or body to others. \\
\hline 5. & $\begin{array}{l}\text { I rarely feel guilty / anxious after eating a high fat / high } \\
\text { calorie food. }\end{array}$ \\
\hline 6. & I can accept a compliment about my appearance. \\
\hline 7. & $\begin{array}{l}\text { If I had to do things that were unhealthy (fasting, laxatives, } \\
\text { throwing up, excess exercise) in order to change (or } \\
\text { maintain my weight), I would choose not to do them. }\end{array}$ \\
\hline 8. & $\begin{array}{l}\text { I feel happy or content, for the most part, with my life at } \\
\text { this time. }\end{array}$ \\
\hline 9. & I wouldn't panic if I gained (or lost) a few kilos. \\
\hline 10 & $\begin{array}{l}\text { For the most part, I am satisfied with my body shape and } \\
\text { size. }\end{array}$ \\
\hline
\end{tabular}


Appendix-2: قائمة تصنيف المواقف تجاه الوزن و المظهر

\begin{tabular}{|c|c|c|}
\hline خطأ & قائمة تصنيف المواقف تجاه الوزن و المظهر & 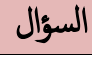 \\
\hline & أنا نادرا ما آتحدث سلبا عن جسدي. & .1 \\
\hline & أنا لا أزن نقي آكثر من مرة في الأسبوع. & .2 \\
\hline & حتي إذا كان المظهر لا عهم في كجمعنا، سوف أظل أمارس نفس الم من الرياضة الذي أفعله الآن. & .3 \\
\hline & 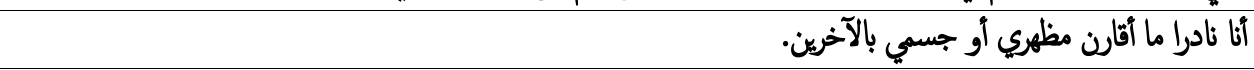 & .4 \\
\hline & أنا نادرا ما أشعر بالذنب أو القلق بعد تناول الأطعمة عالية الدهون أو عالية السعرات الحرارية. & .5 \\
\hline & يكني قبول المديح أو الإطراء علي مظهري. & 6 \\
\hline & 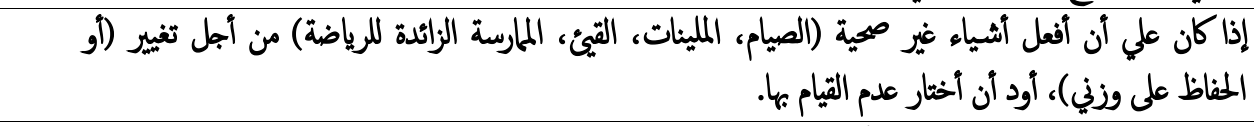 & .7 \\
\hline & أشعر بالسعادة أو الرضا، في معظم الأحيان، عن حياتي في هذا الوقت. . & .8 \\
\hline & أنا لن أصاب بالذعر إذا كنت قدكبت (أو فقدت) بضعة كيلوات. & .9 \\
\hline & بالنسبة للجزء الأكبر، أنا راض عن جسدي شكلا وججا. & .10 \\
\hline
\end{tabular}

